\title{
Increased Gonorrhea Cases — Utah, 2009-2014
}

\begin{abstract}
Joanna Watson, DPhil ${ }^{1,2}$; Jerry Carlile, MSPH ${ }^{2}$; Angela Dunn, MD ${ }^{1,2}$; Megan Evans ${ }^{2}$; Erin Fratto, MS²; Joel Hartsell, MPH²; Lynn Meinor ${ }^{2}$;
\end{abstract} Matthew Mietchen, $\mathrm{MPH}^{2}$; Allyn Nakashima, $\mathrm{MD}^{2}$

Gonorrhea (caused by infection with Neisseria gonorrhoeae) is the second most commonly reported notifiable disease in the United States (1). Left untreated, gonorrhea is associated with serious long-term adverse health effects, including pelvic inflammatory disease, ectopic pregnancy, and infertility. Infection also facilitates transmission of human immunodeficiency virus $(2,3)$. Effective gonorrhea control relies upon early detection and effective antimicrobial treatment. To assess gonorrhea rate trends in Utah, the Utah Department of Health (UDOH) analyzed Utah National Electronic Disease Surveillance System (UT-NEDSS) data for the state during 2009-2014. After declining during 2009-2011, the statewide gonorrhea rate increased fivefold to 49 cases per 100,000 population in 2014. During 2009-2014, the proportion of cases among women increased from $21 \%$ to $39 \%$ (decreasing among males from $79 \%$ to $61 \%$ ). Among male patients, the proportion who identified as men who have sex with men (MSM) decreased from $67 \%$ to $42 \%$. These demographic changes suggest that increased heterosexual transmission of gonorrhea in Utah might be occurring. Health departments need to work with providers to ensure populations at high risk are being screened and properly treated for gonorrhea. Clinicians need to be aware of increases in the risk for infection among women and non-MSM males when making screening and testing decisions and educate their patients regarding gonorrhea transmission and prevention practices.

All cases of gonorrhea reported in Utah during 2009-2014 were included in the analysis. Data reported to UT-NEDSS were obtained from laboratory reports and local health department (LHD) case investigations. The majority of LHDs in Utah attempted to interview all gonorrhea patients. During interviews, LHD personnel obtained demographic information and details of sexual contacts (including, for male patients, sex of sex partner) during the 3 months preceding the diagnosis. LHDs obtained information about diagnosing provider type and treatment from laboratory reports or directly from providers.
For each year during 2009-2014, gonorrhea reporting rates (per 100,000 population overall and by sex, age group, and race/ethnicity) were calculated by dividing the number of laboratory-confirmed gonorrhea cases reported to UDOH by U.S. Census Bureau estimates of the Utah population for that year. Proportions were calculated for the following patient

\section{INSIDE}

894 CDC Grand Rounds: Preventing Suicide Through a Comprehensive Public Health Approach

898 Current Cigarette Smoking, Access, and Purchases from Retail Outlets Among Students Aged 13-15 Years - Global Youth Tobacco Survey, 45 Countries, 2013 and 2014

902 Epidemiology of Varicella During the 2-Dose Varicella Vaccination Program - United States, 2005-2014

906 Carbapenem-Resistant Enterobacteriaceae Transmission in Health Care Facilities - Wisconsin, February-May 2015

910 Guillain-Barré Syndrome During Ongoing Zika Virus Transmission - Puerto Rico, January 1-July 31, 2016

915 Likely Sexual Transmission of Zika Virus from a Man with No Symptoms of Infection — Maryland, 2016

917 Hearing Loss in Infants with Microcephaly and Evidence of Congenital Zika Virus Infection - Brazil, November 2015-May 2016

920 Notes from the Field: Cluster of Lymphogranuloma Venereum Cases Among Men Who Have Sex with Men - Michigan, August 2015-April 2016

922 QuickStats

Continuing Education examination available at http://www.cdc.gov/mmwr/cme/conted_info.html\#weekly.

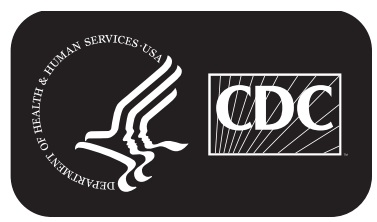

U.S. Department of Health and Human Services Centers for Disease Control and Prevention 
characteristics: sex of partner(s) (for men), diagnosis provider, whether the patient was interviewed by LHD, and whether the patient was treated.

During 2009-2011, the gonorrhea rate in Utah decreased from 12 to 10 cases per 100,000 population, before increasing in 2012, 2013, and 2014, to 17,33, and 49 cases per 100,000, respectively (Table 1). During 2011-2014, the rate was higher among men (range $=14.9-59.2$ ) than among women (range $=4.7-38.5$ ); however, the percentage increase observed during 2011-2014 was substantially greater among women $(715 \%)$ than among men (297\%).

During 2009-2014, rates in Utah were consistently highest among persons aged 20-24 years and 25-29 years. However, the percentage of cases reported among persons in those two age groups combined (20-29 years) decreased each year, from $58 \%$ in 2009 to $49 \%$ in 2014 . Throughout 2009-2014, the gonorrhea rate was highest among non-Hispanic blacks; however, the absolute number of cases was highest among non-Hispanic whites, who accounted for approximately $80 \%$ of Utah's population (Table 1).

The percentage of patients interviewed by LHDs each year ranged from $75 \%$ to $86 \%$, and approximately $96 \%$ of patients had been treated for gonorrhea. During 2009-2014, the proportion of male gonorrhea patients self-reporting as MSM decreased $38 \%$, from $66.8 \%$ to $41.7 \%$ (Table 2) (Figure). The proportion of male gonorrhea patients self-identifying as MSM differed markedly among racial/ethnic populations. During 2014, approximately $51 \%$ of non-Hispanic white men,
$26 \%$ of Hispanic men, and $19 \%$ of non-Hispanic black men self-reported as MSM (Table 2).

The proportion of cases diagnosed at a sexually transmitted disease (STD) clinic decreased from 38\% during 2009 to $20 \%$ during 2014. MSM were substantially more likely to have received a diagnosis at an STD clinic than both non-MSM men and women for all years during 2009-2014 (Table 2).

\section{Discussion}

The national gonorrhea rate declined approximately $74 \%$ during 1975-1997 (1). After 1997, the rate fluctuated, but continued to decrease, reaching an all-time low during 2009. The national rate increased each year during 2009-2012, and after decreasing slightly during 2013, increased again during 2014 (the most recent year for which national data are available) (1). During 2013, the national gonorrhea rate was higher among men than among women for the first time since 2000, and remained higher during 2014. In contrast, during 2000-2014, rates were consistently higher among men than among women in the West census region, including Utah (1). Higher gonorrhea rates among men than women indicate substantial transmission among MSM. However, other factors (e.g., screening or partner notification practices) also can affect the male-to-female case ratio. Although not all states collect such information for gonorrhea cases, in Utah, information on the sex of sex partner(s) is collected for male patients, and until 2012, indicated that the majority of gonorrhea cases in males were among MSM.

The MMWR series of publications is published by the Center for Surveillance, Epidemiology, and Laboratory Services, Centers for Disease Control and Prevention (CDC), U.S. Department of Health and Human Services, Atlanta, GA 30329-4027.

Suggested citation: [Author names; first three, then et al., if more than six.] [Report title]. MMWR Morb Mortal Wkly Rep 2016;65:[inclusive page numbers].

\section{Centers for Disease Control and Prevention}

Thomas R. Frieden, MD, MPH, Director

Harold W. Jaffe, MD, MA, Associate Director for Science

Joanne Cono, MD, ScM, Director, Office of Science Quality

Chesley L. Richards, MD, MPH, Deputy Director for Public Health Scientific Services

Michael F. Iademarco, MD, MPH, Director, Center for Surveillance, Epidemiology, and Laboratory Services

\section{MMWR Editorial and Production Staff (Weekly)}

Sonja A. Rasmussen, MD, MS, Editor-in-Chief

Charlotte K. Kent, PhD, MPH, Executive Editor Jacqueline Gindler, MD, Editor

Teresa F. Rutledge, Managing Editor

Douglas W. Weatherwax, Lead Technical Writer-Editor

Soumya Dunworth, PhD, Teresa M. Hood, MS, Technical Writer-Editors

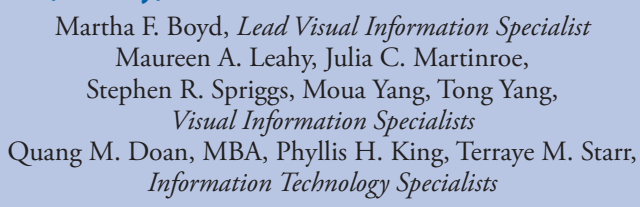
Visual Information Specialists

Quang M. Doan, MBA, Phyllis H. King, Terraye M. Starr, Information Technology Specialists

\section{MMWR Editorial Board}

Timothy F. Jones, MD, Chairman

Matthew L. Boulton, MD, MPH

Virginia A. Caine, MD

Katherine Lyon Daniel, PhD

Jonathan E. Fielding, MD, MPH, MBA

David W. Fleming, MD

\author{
William E. Halperin, MD, DrPH, MPH \\ King K. Holmes, MD, PhD \\ Robin Ikeda, MD, MPH \\ Rima F. Khabbaz, MD \\ Phyllis Meadows, PhD, MSN, RN \\ Jewel Mullen, MD, MPH, MPA
}

\author{
Jeff Niederdeppe, $\mathrm{PhD}$ \\ Patricia Quinlisk, MD, MPH \\ Patrick L. Remington, MD, MPH \\ Carlos Roig, MS, MA \\ William L. Roper, MD, MPH \\ William Schaffner, MD
}


TABLE 1. Number and rate* of gonorrhea cases, by sex, age group, and race/ethnicity — Utah National Electronic Disease Surveillance System, 2009-2014

\begin{tabular}{|c|c|c|c|c|c|c|}
\hline & 2009 & 2010 & 2011 & 2012 & 2013 & 2014 \\
\hline Characteristic & No. (Rate) & No. (Rate) & No. (Rate) & No. (Rate) & No. (Rate) & No. (Rate) \\
\hline Total & $341(12.3)$ & $310(11.0)$ & $277(9.7)$ & $480(16.5)$ & $951(32.8)$ & $1,442(48.9)$ \\
\hline $\begin{array}{l}\text { Sex } \\
\text { Male } \\
\text { Female }\end{array}$ & $\begin{array}{r}271(19.8) \\
70(5.2)\end{array}$ & $\begin{array}{r}235(16.9) \\
75(5.4)\end{array}$ & $\begin{array}{r}211(14.9) \\
66(4.7)\end{array}$ & $\begin{array}{r}348(24.2) \\
132(9.3)\end{array}$ & $\begin{array}{l}578(39.7) \\
373(25.9)\end{array}$ & $\begin{array}{l}878(59.2) \\
564(38.5)\end{array}$ \\
\hline \multicolumn{7}{|l|}{ Age group (yrs) } \\
\hline $\begin{array}{l}15-19 \\
20-24 \\
25-29 \\
30-34 \\
35-39 \\
40-44\end{array}$ & $\begin{array}{r}50(22.7) \\
94(41.3) \\
103(45.0) \\
31(14.6) \\
18(10.3) \\
14(9.3)\end{array}$ & $\begin{array}{r}47(21.3) \\
100(43.8) \\
64(27.7) \\
41(18.8) \\
26(14.6) \\
18(11.6)\end{array}$ & $\begin{array}{r}38(17.4) \\
81(34.7) \\
69(30.6) \\
39(17.4) \\
25(13.7) \\
11(6.8)\end{array}$ & $\begin{array}{r}55(25.1) \\
118(48.8) \\
88(40.4) \\
84(37.0) \\
45(23.5) \\
31(18.7)\end{array}$ & $\begin{array}{r}87(39.1) \\
240(97.6) \\
212(95.6) \\
153(66.2) \\
96(49.3) \\
54(32.1)\end{array}$ & $\begin{array}{r}149(65.5) \\
392(156.5) \\
321(148.4) \\
253(109.2) \\
149(72.8) \\
66(37.9)\end{array}$ \\
\hline \multicolumn{7}{|l|}{ Race/Ethnicity } \\
\hline White, non-Hispanic & $236(10.7)$ & $254(11.4)$ & $206(9.1)$ & $315(13.8)$ & $667(28.8)$ & 930 (38.9) \\
\hline Black, non-Hispanic & $26(100.4)$ & $9(33.9)$ & $20(73.1)$ & $57(198.5)$ & $71(237.4)$ & $99(322.4)$ \\
\hline Hispanic & $60(17.3)$ & $34(9.4)$ & $41(11.1)$ & $83(22.0)$ & $171(44.1)$ & $319(80.5)$ \\
\hline Asian & $4(7.5)$ & $2(3.6)$ & $2(3.5)$ & $3(5.0)$ & $13(20.6)$ & $21(32.8)$ \\
\hline Native Hawaiian/Pacific Islander & $3(12.8)$ & $3(12.3)$ & $3(12.2)$ & $5(19.7)$ & $7(26.8)$ & $18(67.8)$ \\
\hline American Indian/Alaska Native & $2(7.3)$ & $6(22.1)$ & $5(18.3)$ & $14(50.9)$ & $20(71.2)$ & $15(52.6)$ \\
\hline Multiple race & $1(2.2)$ & $0(0)$ & $0(0)$ & $1(2.0)$ & $2(3.7)$ & $5(9.2)$ \\
\hline
\end{tabular}

* Per 100,000 population using U.S. Census Bureau estimates.

TABLE 2. Selected characteristics of reported gonorrhea cases obtained from local health department investigations, including patient interviews - Utah, 2009-2014

\begin{tabular}{|c|c|c|c|c|c|c|c|}
\hline & 2009 & 2010 & 2011 & 2012 & 2013 & 2014 & Total \\
\hline Characteristic & No. (\%) & No. $(\%)$ & No. (\%) & No. (\%) & No. (\%) & No. (\%) & No. (\%) \\
\hline \multicolumn{8}{|c|}{ MSM (\% of male patients) } \\
\hline Yes & $181(66.8)$ & $155(66.0)$ & $130(61.6)$ & $180(51.7)$ & $247(42.7)$ & $366(41.7)$ & $1,259(49.9)$ \\
\hline No & $42(15.5)$ & $39(16.6)$ & $49(23.2)$ & $89(25.6)$ & $227(39.2)$ & $352(40.1)$ & $798(31.7)$ \\
\hline Unknown & $48(17.7)$ & $41(17.5)$ & $32(15.2)$ & 79 (22.7) & $104(18.0)$ & $160(18.2)$ & 464 (18.4) \\
\hline \multicolumn{8}{|c|}{ MSM (\% of white male patients) } \\
\hline Yes & $146(74.1)$ & $131(66.8)$ & $112(67.9)$ & $145(62.5)$ & $205(49.8)$ & $284(50.8)$ & $1,023(58.1)$ \\
\hline No & $16(8.1)$ & $30(15.3)$ & $28(17.0)$ & 46 (19.8) & $133(32.3)$ & $176(31.5)$ & $429(24.4)$ \\
\hline Unknown & $35(17.8)$ & $35(17.9)$ & $25(15.2)$ & $41(17.7)$ & $74(18.0)$ & 99 (17.7) & 309 (17.5) \\
\hline \multicolumn{8}{|c|}{ MSM (\% of black male patients) } \\
\hline Yes & $10(47.6)$ & $2(33.3)$ & $3(25.0)$ & $5(10.9)$ & $4(10.0)$ & $15(19.0)$ & 39 (19.1) \\
\hline No & $8(38.1)$ & $3(50.0)$ & $9(75.0)$ & $24(52.2)$ & $25(62.5)$ & $49(62.0)$ & $118(57.8)$ \\
\hline Unknown & $3(14.3)$ & $1(16.7)$ & $0(0.0)$ & $17(37.0)$ & $11(27.5)$ & $15(19.0)$ & $47(23.0)$ \\
\hline \multicolumn{8}{|c|}{ MSM (\% of Hispanic male patients) } \\
\hline Yes & $19(50.0)$ & $20(71.4)$ & $15(51.7)$ & $24(43.6)$ & $27(26.0)$ & $49(25.8)$ & $154(34.7)$ \\
\hline No & $15(39.5)$ & $3(10.7)$ & $8(27.6)$ & $17(30.9)$ & $62(59.6)$ & $112(58.9)$ & $217(48.9)$ \\
\hline Unknown & $4(10.5)$ & $5(17.9)$ & $6(20.7)$ & $14(25.5)$ & $15(14.4)$ & $29(15.3)$ & 73 (16.4) \\
\hline \multicolumn{8}{|c|}{ Diagnosing provider (MSM only) } \\
\hline STD clinics & $109(60.2)$ & $88(56.8)$ & 74 (56.9) & $94(52.2)$ & $135(54.7)$ & $174(47.5)$ & $674(53.5)$ \\
\hline Other or unknown* & $72(39.8)$ & $67(43.2)$ & $56(43.1)$ & $86(47.8)$ & $112(45.3)$ & $192(52.5)$ & $585(46.5)$ \\
\hline \multicolumn{8}{|c|}{ Diagnosing provider (non-MSM male only) } \\
\hline STD clinics & $15(35.7)$ & $2(5.1)$ & $9(18.4)$ & $22(24.7)$ & $51(22.6)$ & $70(19.8)$ & $169(21.2)$ \\
\hline Other or unknown* & $27(64.3)$ & $37(94.9)$ & 40 (81.6) & $67(75.3)$ & $176(77.4)$ & $282(80.2)$ & $629(78.8)$ \\
\hline \multicolumn{8}{|c|}{ Diagnosing provider (female only) } \\
\hline STD clinics & $3(4.3)$ & $3(4.0)$ & $5(7.6)$ & $17(12.9)$ & $44(11.5)$ & $42(7.4)$ & $114(8.9)$ \\
\hline Other or unknown* & 67 (95.7) & $72(96.0)$ & $61(92.4)$ & $115(87.1)$ & $329(88.5)$ & $522(92.6)$ & $1,166(91.1)$ \\
\hline
\end{tabular}

Abbreviations: MSM = men who have sex with men; STD = sexually transmitted disease.

* Includes emergency department or urgent care, family planning or Planned Parenthood Association of Utah, prenatal or obstetrics, private physician or health maintenance organization, corrections facility, other unspecified providers, and unknown providers. Unknown ranges were $0 \%-3 \%$ among men and $0 \%-1.5 \%$ among women. 
FIGURE. Percentage of male gonorrhea patients who self-reported as men who have sex with men (MSM) - Utah, 2009-2014

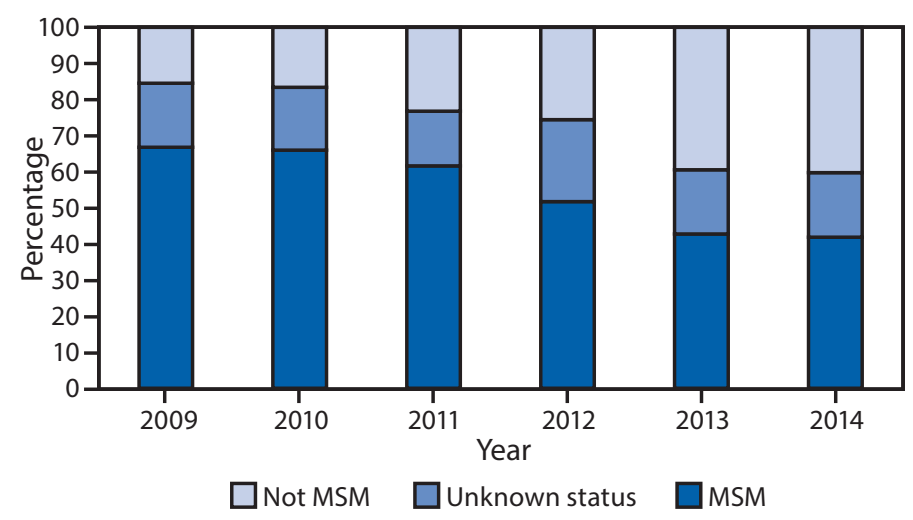

Since 2011, the gonorrhea rate in Utah has increased substantially, with a much larger percentage increase among women than among men. The proportion of male patients self-reporting as MSM has decreased each year since 2009, indicating an expansion of heterosexual transmission of gonorrhea in Utah.

These data indicate that, in Utah, MSM were more likely to have received a diagnosis of gonorrhea from an STD clinic than women and non-MSM men, whereas the proportion of cases diagnosed at STD clinics decreased during 2009-2014. Research conducted in California found that gonorrhea patients who received a diagnosis at STD clinics were more likely to receive treatment that adhered to CDC treatment guidelines than were patients who received a diagnosis in other clinical settings (4). The increase in both proportion and number of gonorrhea cases diagnosed outside of STD clinics underscores the importance of providing education to clinicians regarding local epidemiology of gonorrhea infection, treatment options, and availability of treatment methods, such as expedited partner therapy (5) (prescribing treatment for heterosexual sex partners of gonorrhea patients without physical examination, where legally permitted) (G). Expedited partner therapy for heterosexual sex partners of gonorrhea patients has been available since 2009 in Utah, where it is recommended only in cases where other management strategies are impractical or unsuccessful.

Reviewing public health intervention strategies based on changes in disease epidemiology also provides an opportunity to consider introduction of innovative methods for identifying and providing testing services to persons at high risk. Examples of methods used successfully elsewhere are computerized interviews self-administered to emergency department attendees to ascertain STD testing needs (7), and an Internet-based program to facilitate home STD testing using self-collected vaginal, urethral, and rectal swabs (8).

\section{Summary}

What is already known about this topic?

Until 2013, national gonorrhea rates among women were slightly higher than rates among men. The reported gonorrhea rate has increased each year since 2009, with the exception of a slight decrease during 2013. In contrast to national rates, multiple Western states have consistently reported substantially higher gonorrhea rates among men than among women, indicating high transmission levels among men who have sex with men (MSM). However, MSM status of patients is not always ascertained.

What is added by this report?

During 2009-2011, the gonorrhea rate in Utah decreased from 13 to 10 cases per 100,000 population, then increased to 17 cases in 2012 , and 49 cases in 2014. The rate continued to be higher among men than among women; however, the increase was larger among women. Utah has collected reliable data regarding the sex of male gonorrhea patients' sex partners since 2009. The proportion of gonorrhea patients in Utah who self-reported as MSM decreased from $67 \%$ in 2009 to $42 \%$ in 2014 . The proportion of gonorrhea patients in Utah who described themselves as MSM differed substantially by race/ethnicity.

What are the implications for public health practice?

Changes in case population demographics in Utah are indicative of an expansion in gonorrhea transmission to new sexual networks, with increased heterosexual transmission. This information will help to guide targeting of gonorrhea testing, treatment, and public health interventions.

In response to the increase in gonorrhea in Utah, UDOH formed a collaborative workgroup with multiple Utah LHDs. To gain a fuller understanding of the increase and the demographic changes associated with it, the workgroup developed a supplemental survey that was added to gonorrhea case investigation interviews during May-August 2014. The survey addressed the following topics: symptoms before diagnosis; health insurance; student status; places where patients met sex partners; sex with anonymous partners; drug and alcohol use; incarceration (of patient or partners); and gender (male, female, or transgender) of patients' sex partners. The survey findings will be used to guide a case-control study to identify risk factors for gonorrhea infection among adult Utah residents.

The findings in this report are subject to at least two limitations. First, reporting of all gonorrhea cases to public health officials is unlikely for a number of reasons, including underreporting by laboratories and providers, failure of infected persons to access care, and misdiagnosis. However, no substantial changes in gonorrhea testing or reporting methods were identified during 2009-2014; therefore, these factors are unlikely to account for the reported increase in diagnoses and reporting. Second, case interview data are missing for $14 \%-24 \%$ of patients, because of LHDs' inability to contact 
the patient, not attempting to contact the patient, or patients declining to be interviewed.

Because of increasing numbers of gonorrhea cases in Utah, identifying populations at high risk is important to develop effective public health interventions. With likely increased heterosexual transmission and changes in the way patients are accessing services in Utah, health departments need to work with providers to ensure populations at high risk are being screened and properly treated for gonorrhea. In areas of the United States where gonorrhea has historically been associated with MSM, the public needs to be made aware of the potential for transmission into previously unaffected sexual networks, and the importance of STD testing for populations at risk needs to be reinforced. Clinicians need to be aware of changes in the risk for infection among women and non-MSM males when making screening and testing decisions and recommendations and educate their patients regarding gonorrhea transmission and prevention practices. Analysis of existing data and collection of additional data by other jurisdictions with substantial gonorrhea transmission among MSM might provide important information about whether similar demographic changes in reported gonorrhea cases are occurring in these areas as well.

\section{Acknowledgments}

Utah local health departments; Sarah Kidd, MD, Monica Patton, MD, Emily Weston, MPH, Division of STD Prevention, National Center for HIV/AIDS, Viral Hepatitis, STD, and TB Prevention, CDC.

\author{
${ }^{1}$ Epidemic Intelligence Service, CDC; ${ }^{2}$ Utah Department of Health. \\ Corresponding author: Joanna Watson,wgq6@cdc.gov, 509-354-8063.

\section{References}

1. CDC. 2014 Sexually transmitted diseases surveillance: gonorrhea. Atlanta, GA: US Department of Health and Human Service, CDC; 2015. http:// www.cdc.gov/std/stats14/gonorrhea.htm

2. Fleming DT, Wasserheit JN. From epidemiological synergy to public health policy and practice: the contribution of other sexually transmitted diseases to sexual transmission of HIV infection. Sex Transm Infect 1999;75:3-17. http://dx.doi.org/10.1136/sti.75.1.3

3. Walker CK, Sweet RL. Gonorrhea infection in women: prevalence, effects, screening, and management. Int J Womens Health 2011;3:197-206.

4. Lechtenberg RJ, Samuel MC, Bernstein KT, Lahiff M, Olson N, Bauer HM. Variation in adherence to the treatment guidelines for Neisseria gonorrhoeae by clinical practice setting, California, 2009 to 2011. Sex Transm Dis 2014;41:338-44. http://dx.doi.org/10.1097/ OLQ.0000000000000113

5. CDC. Guidance on the use of expedited partner therapy in the treatment of gonorrhea. Atlanta, GA: US Department of Health and Human Services, CDC; 2015. http://www.cdc.gov/std/ept/gc-guidance.htm

6. CDC. Legal status of expedited partner therapy (EPT). Atlanta, GA: US Department of Health and Human Services, CDC; 2016. http://www. cdc.gov/std/ept/legal/

7. Ahmad FA, Jeffe DB, Plax K, et al. Computerized self-interviews improve Chlamydia and gonorrhea testing among youth in the emergency department. Ann Emerg Med 2014;64:376-84. http://dx.doi. org/10.1016/j.annemergmed.2014.01.031

8. Gaydos CA, Barnes M, Jett-Goheen M, et al. Characteristics and predictors of women who obtain rescreening for sexually transmitted infections using the www.iwantthekit.org screening programme. Int J STD AIDS 2013;24:736-44. 